ISSN: 2146-3042

DOI: 10.25095/mufad.510663

\title{
Borsa İstanbul'da İşlem Gören Çimento Firmalarının Finansal Performansının Analizi
}

\author{
M. Esra ATUKALP*
}

\section{$\ddot{O Z Z T}$}

$\mathrm{Bu}$ çalışmanın amacı, Borsa İstanbul Taş, Toprak Endeksinde yer alan çimento firmalarının finansal performanslarını incelemektir. Analiz yöntemi olarak çok kriterli karar verme tekniklerinden olan Multi-MOORA (Multi-Objective Optimization on the basis of Ratio Analysis), analiz dönemi olarak 2013-2017 dönemi ele alınmıştır. Analiz sonucunda en iyi finansal performansa sahip olan çimento firmasının Ünye Çimento olduğu belirlenmiştir.

Anahtar Kelimeler: Finansal Performans, Borsa İstanbul, Çimento Sektörü, MOORA JEL Sinıflandırması: L21, L25

\section{Analysis of Financial Performance of Cement Firms Traded on Borsa İstanbul}

\section{ABSTRACT}

The aim of this study is to examine the financial performances of the cement firms on Borsa Istanbul Non-metal min. product Index. Multi-MOORA (Multi-Objective Optimization on the basis of Ratio Analysis), which is one of the multi-criteria decision making techniques, was used as the analysis method and 2013-2017 period was analyzed as the analysis period. As a result of the analysis, it is determined that the cement company having the best financial performance is Ünye Cement.

Keywords: Financial Performance, Borsa İstanbul, Cement Sector, MOORA

Jel Classification: L21, L25

\footnotetext{
* Dr. Öğr. Üyesi, Giresun Üniversitesi, Bulancak Uygulamalı Bilimler Yüksekokulu, esra.atukalp@ gmail.com, ORCID ID: 0000-0001-8412-1448
} 


\section{GIRIŞ}

Çimento sektörü, yüksek yatırımlar gerektiren, piyasaya giriş ve çıkışın zor olduğu ve yatırımların faaliyete geçirilmesinin zaman aldığı bir sektör olması nedeniyle arz esnekliğinin düşük, yoğunlaşmanın yüksek olduğu bir sektör olarak kabul edilebilir (Rekabet Kurumu, 2016: 15). Öte yandan yurtiçinde artan rekabet ve oluşan kapasite fazlası Türk çimento firmalarının alternatif pazarlara yönelerek büyümeyi hedeflemelerini sağlamıştır (TSKB, 2018: 40).

Çimento, nakliyesinin maliyetli olması nedeniyle bölgesel olarak üretilen, genellikle tüketimi bölgesel yapılan bir mamuldür. Söz konusu maliyetlerin ürün değerine oranı, çimentonun ekonomik olarak pazarlanabileceği coğrafyanın belirlenmesinde önemli olmakta; bu da çimento fabrikalarının kuruldukları pazar ve çevresinde yüksek pazar gücüne sahip olmalarını kolaylaştırmaktadır (Rekabet Kurumu, 2016: 15).

Türkiye'de sektöre ilişkin yapılan 2017 dönemini içeren incelemelerde, çimento sektörünü etkileyen enerji maliyetlerindeki artışlar ve bunların satış fiyatlarına yansıtılamamasının kâr marjlarındaki azalışta etkili olduğu belirtilmektedir. Ayrıca, özellikle konut sektörüne yapılan satışlar, sektörde alacakların vadelerinde uzamaya, bu da firmalar için banka kredisi kullanımında artışa neden olmaktadır. (TSKB, 2018: 41)

Çimento firmaları da dahil olmak üzere tüm firmalarda finansal göstergelerin ele alınması suretiyle yapılan performans incelemesinde kullanılan, farklı yaklaşıma sahip analiz yöntemleri bulunmaktadır. Öte yandan ekonominin bütünü ve tüm finansal kurumlar için dönem farklılıkları da performans değişikliklerine sebep olabilmektedir.

$\mathrm{Bu}$ çalışmanın amacı Borsa İstanbul Taş, Toprak Endeksinde yer alan çimento firmalarıın finansal performanslarını çok kriterli karar verme tekniklerinden olan MultiMOORA ile incelemektir.

Çalışmada bu doğrultuda ilk önce Türkiye'de çimento sektörü hakkında açıklayıcı bilgi verilmiş ve araştırma konusu hakkında literatür incelemesi yapılmıştır. Daha sonra kullanılacak yöntem açıklanmış, araştırma kapsamındaki çimento firmalarına ilişkin analiz bulguları değerlendirilmiş, sonuç kısmında ise çalışmanın genel değerlendirmesine yer verilmiştir.

\section{TÜRKIYE'DE ÇIMMENTO SEKTÖRÜ}

İnşaat ve yapı malzemeleri sektörünün en temel girdilerinden olan çimentonun dünyada yıllık tüketimi 4-4,2 milyar ton civarındadır. Dünya çimento tüketiminde, gelişmekte olan ve nüfus gelişimi hızlı ülkeler önde gelmektedir (TSKB; 2018: 8).

Türkiye'de iç göç hareketlerinin yoğunluğu, kentleşmedeki artış, genç nüfusun yoğunluğu ve toplum tarafindan konut sektörünün yatırım aracı olarak görülmesinin de etkisiyle inşaat sektörü Türkiye'de geçmişte olduğu gibi günümüzde öneme sahiptir (TSKB, 2018: 9). İnşaat sektöründeki gelişmeler, yarattı̆̆ talep dolasıyla çimento sektörünü; çimento sanayiindeki gelişmeler de inşaat sektörünü etkilemektedir. 
Türkiye'de çimento sektörü oligopol piyasa yapısına sahiptir. Çimento fabrikaları hammaddeye ve yerleşim bölgelerine yakın yerlerde yoğunlaşmaktadır. Bununla birlikte, çimentonun sadece karayolu ile taşınabildiği iç bölgelerde rekabetçiliğin düşmesi nedeniyle fabrika sayısı daha azdır. (Türkiye İş Bankası, 2016: 10)

Türkiye'de faaliyet göstermekte olan çimento fabrikaları Tablo 1'de gösterilmektedir.

Tablo 1. Türkiye'de Faaliyet Gösteren Çimento Fabrikaları ${ }^{1}$

\begin{tabular}{|l|l|}
\hline AS Çimento San. ve Tic. A.Ş. & Kahramanmaraş Çimento Beton San.ve İşletmesi A.Ş. \\
\hline Baştaş Çimento Sanayi A.Ş. & LiMÇiM Çimento Sanayi ve Ticaret A.Ş. \\
\hline Bursa Çimento Fabrikası A.Ş. & Adana Çimento Sanayi T.A.Ş. \\
\hline Denizli Çimento Sanayi T.A.Ş. & Aslan Çimento A.Ş. \\
\hline Göltaş Göller Bölgesi Çimento San. ve Tic. A.Ş. & Bolu Çimento Sanayi A.Ş. \\
\hline Konya Çimento San. A.Ş. & Mardin Çimento Sanayii Ticaret A.Ş. \\
\hline MEDCEM Madencilik ve Yapı Malzemeleri A.Ş. & Ünye Çimento Sanayi ve Tic. A.Ş. \\
\hline Nuh Çimento Sanayi A.Ş. & Çimsa Çimento Sanayi ve Ticaret A.Ş. \\
\hline Adoçim Çimento Beton San. ve Tic. A.Ş. & Bartın Çimento San. ve Tic. A.Ş. \\
\hline Akçansa Çimento Sanayi ve Ticaret A.Ş. & Limak Batı Çimento San. ve Tic. A.Ş. \\
\hline Aşkale Çimento Sanayi T.A.Ş. & Afyon Çimento Sanayii T.A.Ş. \\
\hline SANÇìM Bilecik Çimento Madencilik Beton San. Tic. A.Ş. & YURTÇiM/ Yurt Çimento San. Tic. ve A.Ş. \\
\hline Batı̧im Batı Anadolu Çimento Sanayi A.Ş. & Votorantim Çimento Sanayi ve Ticaret A.Ş. \\
\hline Batısöke Söke Çimento Sanayi T.A.Ş. & SEZA Çimento-SYCS İnşaat Çimento San. ve Tic. A.Ş. \\
\hline Çimentaş Çimento Fabrikası T.A.Ş. & \\
\hline
\end{tabular}

Kaynak: http://www.tcma.org.tr/index.php?page=icerikgoster\&menuID=28, 2018

Çimento sektöründe tesise göre değişiklik göstermekle birlikte maliyetin yaklaşık \% 60'ının petrokok ve elektrik fiyatlarından oluşması sonucu, 2016 yılının ikinci yarısından sonra enerji ve elektrik fiyatlarındaki artışlar üretim maliyetlerinde artışa ve kârlılıkların düşmesine neden olmuştur. Kâr marjındaki azalmada maliyetlerdeki artışların enerji fiyatlarına yansitılamaması da etkilidir (TSKB, 2018: 38-41).

Çimento sektörüne ilişkin üretim ile yurtiçi satış ve ihracat miktarı 2010-2017 dönemi itibariyle gösteren Grafik 1 incelendiğinde 2010 haricindeki yıllarda üretimin tamamının satıldığ1 görülmektedir. Üretimin toplam satıştan daha az olduğu 2010 yılında ise stokun satışa destek olduğu kaynak verilerine göre belirtilebilir.

\footnotetext{
${ }^{1}$ Söz konusu çimento fabrikaların bir kısmının farklı illerde şubeleri bulunmaktadır. Verilen kaynağa göre çimento fabrikalarının Türkiye'deki coğrafi bölgelerdeki sayısı şu şekildedir: İç Anadolu Bölgesi-16; Marmara Bölgesi-15; Karadeniz Bölgesi-10; Akdeniz Bölgesi-9; Doğu Anadolu Bölgesi-8; Güneydoğu Anadolu Bölgesi7; Ege Bölgesi-6.
} 
Grafik 1. Türkiye Çimento Sektörü Üretim ve Satı̧̧ Göstergeleri (ton)

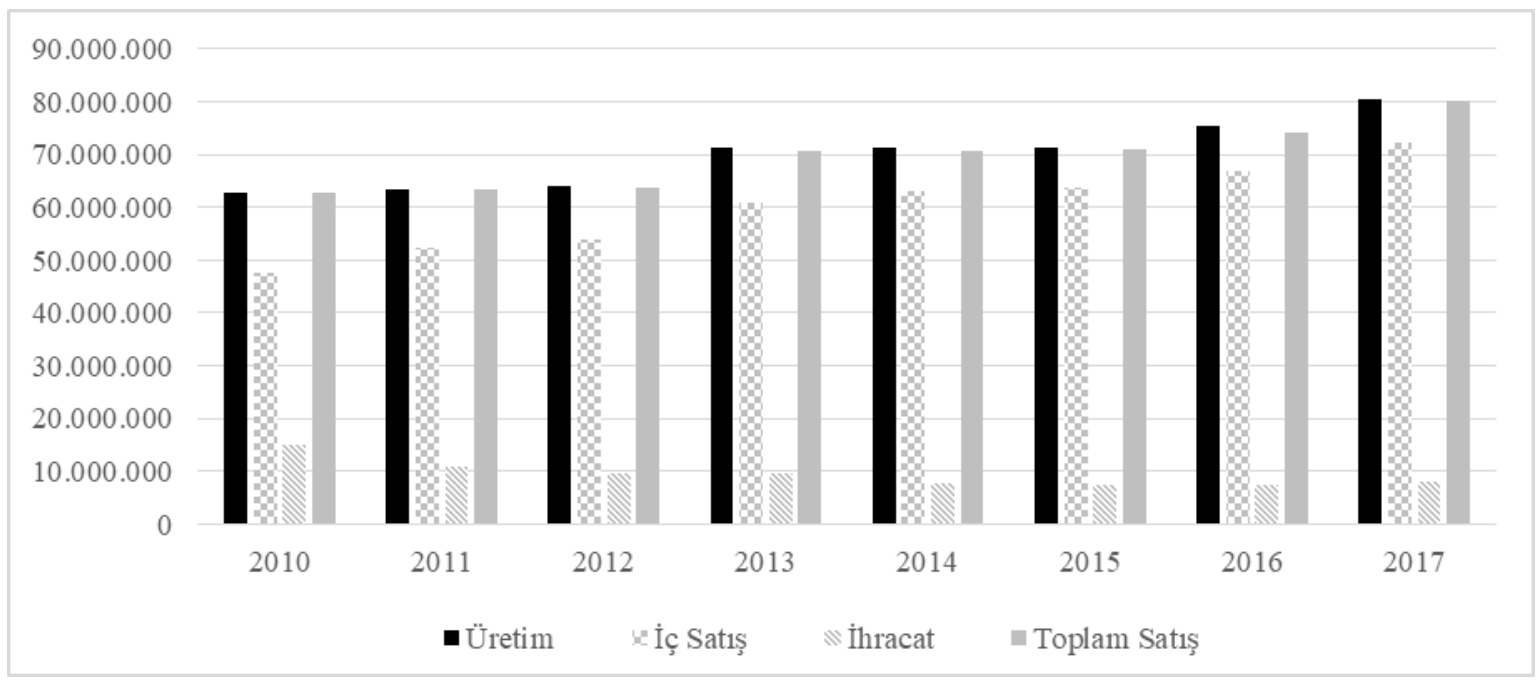

Kaynak: Türkiye Çimento Müstahsilleri Birliği “Üretim-Satış-Stok Tablosu” verileri esas alınarak düzenlenmiştir. (http://www.tcma.org.tr/index.php?page=icerikgoster\&menuID=38)

Çimento iç satışının Türkiye'de bölgelere ilişkin dağılımı ele alındığında toplam satışın, \% 27'sinin Marmara, \% 19'unun İç Anadolu, \% 17'sinin Akdeniz, \% 13'ünün Karadeniz, \% 9'unun Doğu Anadolu, \% 7,9'unun Güneydoğu Anadolu ve \% 7,5'inin de Ege Bölgelerinde yapıldı̆̆ söylenebilir (http://www.tcma.org.tr) ${ }^{2}$.

Nakliyesinin maliyetli olması nedeniyle bölgesel olarak üretildiği belirtilen çimentonun, genellikle tüketiminin de bölgesel yapıldığ 1 bilgisi (Rekabet Kurumu, 2016: 15) çimento fabrikalarının sayı olarak fazla olduğu bölgelerde iç satışın fazla olmasını açıklamaktadır.

\section{LITERATÜR İNCELEMESI}

Firmaların performanslarını değerlendirmek yatırımcılar, hissedarlar ve alacaklılar için öneme sahiptir. Mali tablolarından yararlanarak ilgili firmaların finansal performans değerlendirmesini gerek dönemler itibariyle bireysel gerekse diğer firmalarla kıyaslamalı olarak yapmak mümkün olmaktadır.

Performans değerlendirme sonuçları, firmaların çevresini oluşturan tüm paydaşlar kadar araştırmacıların da ele aldığı bir husustur. Bu doğrultuda farklı sektörlerde yer alan firmaların farklı karar noktalarına ilişkin performans değerlendirmesi yapan çalışmalar bulunmaktadır. Farklı karar noktalarına ilişkin söz konusu çalışmalar, gerek firmaların bir bütün olarak ele alınması suretiyle yapılan veya şube bazında finansal performans değerlendirmesi çalışmaları, gerekse depo yeri seçimi gibi finansal bir araştırma içermeyen, işletme süreçlerinde verilecek karara ilişkin değerlendirmeler şeklinde ele alınmaktadır. $\mathrm{Bu}$ çalışmada finansal performans değerlendirmesine ilişkin literatür incelemesi yapılmıştır.

\footnotetext{
${ }^{2}$ Bu bilgiler http://www.tcma.org.tr/index.php?page=icerikgoster\& menuID=43 adresindeki 2017 yılına ait "Satış Dağılımı" istatistiklerinden yararlanılarak hazırlanmıştır.
} 
Firmaların finansal performanslarının değerlendirilmesinde farklı teknikler kullanılmakla birlikte, bunlar arasında çok kriterli karar verme teknikleri de kullanılmaktadır. Söz konusu tekniklerden olan MOORA tekniği ile yapılan çalışmalar incelendiğinde de farklı sektörlerde ve farklı karar kriterleri esas alınarak alternatiflerin değerlendirilmesi gerçekleştirilmiştir. Çalışmanın bu kısmında çimento firmaları temel alınarak MOORA yöntemi başta olmak üzere çok kriterli karar verme teknikleri ile yapılan değerlendirme çalışmalarından bir kısmı incelenmiştir.

Karsak ve İşcan (2000), çimento sektöründe faaliyet gösteren ve İstanbul Menkul Kiymetler Borsası'na (İMKB) kote 14 firmanın 1997 yılı verilerini kullanarak, firmaların göreli faaliyet performanslarının değerlendirilmesini yaptıkları çalışmalarında, veri zarflama analizi ile birlikte ağırlık kısıtlamaları ve çapraz etkinlik ölçütlerinin bir arada kullanılmasını önermişlerdir. Bulunan sonuçlara göre, Charnes-Cooper-Rhodes (CCR) modeline ağırlık kısıtlamaları eklenmesi sonucunda etkin olarak belirlenen beş firmanın, çapraz etkinlik analizi sonucu faaliyet etkinliği sıralaması Batı Çimento, Ünye Çimento, Afyon Çimento, Göltaş ve Bursa Çimento olarak belirlenmiştir.

Ertuğrul ve Karakaşoğlu (2009), çalışmalarında İMKB'de bulunan 15 çimento firmasının finansal performansını, çok kriterli karar verme tekniklerinden bulanık analitik hiyerarşi süreci (AHP) ve TOPSİS metodu ile hesaplamışlardır. Kriterlerin ağırlıklarının belirlenmesi sonrası firmaların performans sırası ortaya konulmuştur. Finansal performans açısından Adana Çimento ilk sırada yer almaktadır. Adana Çimento’yu Bolu ve Mardin Çimento izlemektedir.

Dumanoğlu (2010) çalışmasında, İMKB'de işlem görmekte olan çimento firmalarının 2004-2009 döneminde mali performanslarını TOPSİS yöntemi ile analiz etmiştir. Analiz sonucunda bazı firmaların grup içi sıralamasını istikrarlı bir şekilde koruduğu, bazılarının sıralamadaki yerinin iyileştiği, bazı firmaların ise başarısız bulunduğu yönünde tespitlerde bulunmuştur.

Cenger (2011) çalışmasında İMKB'de işlem gören çimento sektörüne ait firmaların etkinlik değerlerini, veri zarflama analizi (VZA) yöntemiyle hesaplayarak sektöre ilişkin performans sonuçları elde etmiştir. Çalışma sonucunda ölçeğe göre sabit getiri modeli bulgularına göre, çimento firmalarının \% 75 'inin verimli faaliyet gösterdiği belirlenmiştir.

Özden vd. (2012), İMKB'de işlem gören çimento sektöründeki firmalarının finansal performanslarını VIKOR yöntemi ile inceledikleri çalışmalarında, 2011 yılının finansal göstergelerini kriter olarak ele almışlardır. Yapılan analiz sonucunda finansal performansı en yüksek olan firma Konya Çimento, en düşük firma ise Afyon Çimento olarak belirlenmiştir. Bunun yanı sıra hisse başına elde edilen getiri sıralamaları ile VIKOR ile elde edilen sıralamalar karşılaştırıldığında anlamlı bir ilişki olmadığ 1 tespit edilmiştir.

Rezaie vd. (2014), çalışmalarında Tahran Borsası'nda faaliyet gösteren 27 İran çimento firmasının 2008-2009 yılı performanslarını entegre bulanık AHP-VIKOR yöntemi ile değerlendirmişlerdir. VİKOR analizi sonucuna göre Ghaen, Urmia ile Fars ve Khoozestan çimento firması 2008 yılında, Hormozgan firması ise 2009 yılında en üst performansa sahip firmalar olarak belirlenmiştir. 
Sakarya ve Akkuş (2015) çalışmalarında, pay senetleri Borsa İstanbul'da (BİST) işlem görmekte olan ve çimento sektöründe faaliyet gösteren firmaların 2010-2013 y1lları arasındaki finansal performanslarını TOPSİS yöntemi ile analiz etmişlerdir. Çalışmada ilk olarak firmaların geleneksel finansal oranları ve nakit akım oranları hesaplanmış ve analiz sonucunda elde edilen bulgulara göre, geleneksel oranlara ve nakit akım oranlarına göre firmaların finansal performansları farklılık gösterdiği ortaya konulmuştur.

Ömürbek ve Özcan (2016) çalışmalarında, BISST'te sigorta sektöründe faaliyet gösteren 6 sigorta firmasını, MOORA yöntemi kullanılarak bazı finansal oranların yardımıyla değerlendirmişlerdir. Çalışmada BİST'te faaliyet gösteren sigorta firmaları, mali durumları açısından karşılaştırılarak, sigortalar arası bir derecelendirmeye ulaşılmaya çalışılmıştır.

Ceyhan ve Demirci (2017) çalışmalarında, BİST'te faaliyet gösteren 6 finansal kiralama firmasını, ele aldıkları finansal oranlar yardımıyla MULTIMOORA yöntemi ile analiz etmiş ve performans sonuçlarına ulaşmışlardır. Analiz sonuçlarına göre finansal performans açısından Yapı Kredi Finansal Kiralama A.O.'nun ilk sırada, Şeker Finansal Kiralama A.Ş.'nin ise son sırada yer aldığı belirtilmektedir.

Metin vd. (2017) çalışmalarında, pay senetleri BİST’te işlem gören 11 enerji firmasının 2010-2015 dönemine ilişkin finansal performanslarını, finansal performansın ölçümü ve değerlendirilmesinde en sık kullanılan çok kriterli karar verme yöntemlerinden olan TOPSIS ile en basit ve en güvenilir olduğu düşünülen MOORA ile analiz etmişlerdir. Analiz sonuçlarına göre, firmaların finansal performanslarının iki yönteme göre değişkenlik gösterdiği tespit edilmiştir. Her iki yöntemde, sadece üç firmanın performans sıralamasının birbirine eşit çıktığı, tüm yıllarda en iyi veya en kötü performansı sergileyen tek bir firmanın olmadığı sonucuna ulaşılmıştır.

Ege ve Yaman (2017) çalışmalarında, BİST çimento firmalarının 2010-2016 yılları arası 6 aylık verilerini ele alınarak, her dönem için TOPSİS ve MOORA yöntemleri ile firmaların finansal performanslarını belirlemiş ve bulunan finansal performansın firmaların pay getirileri üzerine etkilerini incelemişlerdir. Analiz sonuçlarına göre, TOPSİS skorları pay getirileri üzerinde anlamlı pozitif etkiye sahip iken, MOORA skorları pay getirileri üzerinde herhangi bir anlamlı etkiye sahip bulunmamıştır.

Ömürbek ve Aksoy (2017) çalışmalarında imalat sektörünün, Ulusal Verimlilik İstatistik verileri açısından 2005-2015 y1lları arasında en iyi performansı gösterdiği yılın belirlenmesini ve imalat sektörünü oluşturan 32 farklı imalat alt sektörünün 2005-2015 y1lları arasındaki performanslarının değerlendirilmesini amaçlamışlardır. Analiz yöntemi olarak Multi-MOORA yönteminin kullanıldığı çalışmada, 2015 yılının en iyi performansın gösterildiği dönem olduğu, diğer ulaşım araçlarının imalatı alt sektörünün de en iyi performans gösteren imalat alt sektörü olduğu belirlenmiştir.

Raikar (2018) çalışmasında, Hindistan çimento sektörünün ve seçilmiş bazı çimento firmalarının finansal performanslarını, çok kriterli karar verme tekniklerinden AHP ve VİKOR ile hesaplamıştır. Kullanılan metodoloji ve verilere dayanarak en iyi üç çimento firması Ambuja Çimento, Ultra Tech Çimento ve Orient Çimento olarak tespit edilmiştir. 


\section{YÖNTEM VE VERİ}

İşletmelere ilişkin yapılan performans değerlendirme çalışmalarında birçok analiz tekniği kullanılmaktadır. Çok kriterli karar verme teknikleri, bu konuda başvurulabilecek analiz tekniklerindendir. Çalışmada, Borsa İstanbul kapsamında Taş, Toprak (BIST XTAST) endeksinde yer alan çimento firmalarının finansal performansları, Multi-MOORA tekniği kullanılarak analiz edilecektir.

\subsection{Yöntem}

Oran analizine dayalı çok amaçlı optimizasyon olarak adlandırabileceğimiz MOORA (Multi-Objective Optimization on the basis of Ratio Analysis) yöntemi, ayrık alternatiflerle çok amaçlı optimizasyon için önerilmiş bir yöntemdir (Brauers ve Zavadskas, 2006: 445).

MOORA tekniği, çok kriterli karar verme tekniklerinin (ÇKKVT) performans karşılaştırmasına göre diğer tekniklerle kıyaslandığında, tercih edilmesi noktasında avantajlı bir tekniktir. Bu duruma ilişkin performans karşılaştırması Tablo 2'de verilmiştir.

Tablo 2. Çok Kriterli Karar Verme Tekniklerinin Performans Karşılaştırması

\begin{tabular}{|l|l|l|l|l|l|}
\hline ÇKKVT & $\begin{array}{l}\text { Hesaplama } \\
\text { Zamanı }\end{array}$ & Basitlik & $\begin{array}{l}\text { Matematiksel } \\
\text { Hesaplamalar }\end{array}$ & Güvenilirlik & Bilgi Düzeyi \\
\hline MOORA & Çok $a z$ & Çok basit & Asgari & Iyi & Nicel \\
\hline AHP & Çok fazla & Çok kritik & Azami & Zayıf & Karma \\
\hline TOPSiS & Orta & Orta kritik & Orta & Orta & Nicel \\
\hline VIKOR & Az & Basit & Orta & Orta & Nicel \\
\hline ELECTRE & Çok & Orta kritik & Orta & Orta & Karma \\
\hline PROMETHEE & Çok & Orta kritik & Orta & Orta & Karma \\
\hline
\end{tabular}

Kaynak: Brauers ve Zavadskas, 2012: 5.

MOORA tekniği, birden çok metotla yapılabilmektedir. Multi-MOORA ise, söz konusu metotlara ait sonuçların birlikte değerlendirilmesi ile uygulanmaktadır. MOORA metotları olan, oran metodu, referans noktası yaklaşımı ve tam çarpım formunun sonuçlarının birlikte değerlendirilmesi ile elde edilen Multi-MOORA diyagramı Şekil 1'de verilmiştir.

Şekil 1. Multi-MOORA Diyagramı

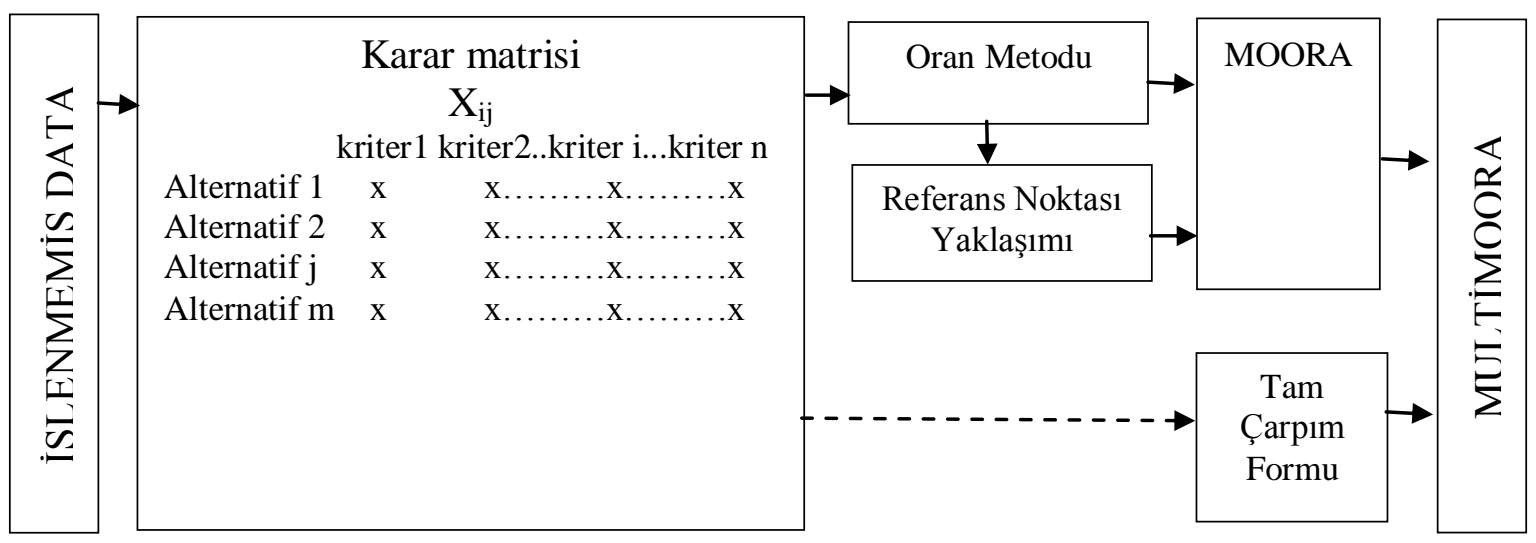

Kaynak: Brauers ve Zavadskas, 2012: 8 ; Baležentis vd., 2010: 585. 
MOORA tekniği ile değerlendirme yapılırken ilk önce farklı alternatiflerin farklı kriterlere karşılık gelen değerlerinden oluşan karar matrisi hazırlanmaktadır. Karar matrisi Şekil 2'de gösterilmektedir. Burada kriterlerin hedeflerinin maksimum ya da minimum olduğu belirlenmelidir.

Şekil 2. Karar Matrisi

\begin{tabular}{|c|c|c|c|c|c|c|}
\hline & Kriter 1 & Kriter 2 & $\ldots \ldots \ldots$ & Kriter i & $\ldots \ldots \ldots$ & Kriter $\mathrm{n}$ \\
\hline Alternatif 1 & $X_{11}$ & $X_{21}$ & ......... & $X_{\mathrm{i} 1}$ & ......... & $X_{n 1}$ \\
\hline Alternatif 2 & $\mathrm{X}_{12}$ & $\mathrm{X}_{22}$ & ........ & $\mathrm{X}_{\mathrm{i} 2}$ & $\ldots \ldots \ldots$ & $X_{n 2}$ \\
\hline …..... & X.. & X.. & 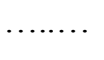 & X.. & …..... & X.. \\
\hline Alternatif $\mathrm{j}$ & $\mathrm{X}_{1 \mathrm{j}}$ & $\mathrm{X}_{2 \mathrm{j}}$ & $\ldots \ldots \ldots$ & $\mathrm{X}_{\mathrm{ij}}$ & $\ldots \ldots \ldots$ & $\mathrm{X}_{\mathrm{nj}}$ \\
\hline .. & X.. & X.. & ........ & X.. & ........ & X.. \\
\hline Alternatif $\mathrm{m}$ & $\mathrm{X}_{1 \mathrm{~m}}$ & $\mathrm{X}_{2 \mathrm{~m}}$ & $\ldots \ldots \ldots$ & $\mathrm{X}_{\mathrm{im}}$ & $\ldots \ldots \ldots$ & $\mathrm{X}_{\mathrm{nm}}$ \\
\hline
\end{tabular}

Kaynak: Brauers ve Zavadskas, 2012: 7.

MOORA tekniğinin metotlarında ilki olan oran metodunda, karar matrisinde yer alan alternatiflere ait kriterler Eşitlik 1'de gösterildiği gibi normalize edilmektedir (Brauers ve Zavadskas, 2006: 447).

$$
\begin{aligned}
& x_{i j}^{*}=\frac{x_{i j}}{\sqrt{\sum_{j=1}^{m} x_{i j}^{2}}} \\
& x_{i j}^{*} \quad=\text { alternatif } j \text { 'nin kriter i üzerindeki normalleştirilmiş kriter değeri } \\
& x_{i j} \quad=\text { alternatif } \mathrm{j} \text { 'nin kriter i üzerindeki yanıtı } \\
& \underset{, 2, \ldots \mathrm{n})}{\mathrm{j}} \quad=\text { alternatif sayıs } \quad(\mathrm{j}=1,2, \ldots, \mathrm{m}) \quad \mathrm{i} \quad=\text { kriter sayıs }(\mathrm{i}=1 \\
& y_{j}^{*}=\sum_{i=1}^{i=g} x_{i j}^{*}-\sum_{i=g+1}^{i=n} x_{i j}^{*} \\
& y_{j}^{*}=\text { alternatif } \mathrm{j} \text { 'nin tüm kriterlere göre normalize edilmiş değerlendirmesi. } \\
& \text { i } \quad=1,2, \ldots, \mathrm{g} \text { maksimize edilecek kriterler } \\
& \text { i } \quad=g+1, g+2, \ldots, n \text { minimize edilecek kriterler; }
\end{aligned}
$$


Diğer bir MOORA metodu olan referans noktası yaklaşımı için, 3 no’lu eşitlik uygulanır. Ele alınan kriterin hedefi maksimizasyon ise ilgili kriter için normalize edilmiş olan $\left(x_{i j}^{*}\right)$ en yüksek değer, hedefi minimizasyon ise en düşük değer referans $\left(\mathrm{r}_{\mathrm{i}}\right)$ kabul edilir (Brauers ve Zavadskas,2006: 447-448). Bu değerler arasındaki farkın mutlak değeri $\left(\left|r_{i}-x_{i j}^{*}\right|\right)$ alınır ve çıkan sonuçlar ile yeni bir matris oluşturulmuş olur. Bu matriste her bir alternatifin en yüksek değerli kriteri belirlenir ve bu değer ilgili alternatifin değeri olarak kabul edilmektedir. Her bir alternatif için hesaplanan bu değerler sıralandığında ise en küçük değere sahip olan alternatif, öncelikli seçilen alternatif olmaktadır.

$$
\min _{(j)}\left\{\max _{(i)}\left|r_{i}-x_{i j}^{*}\right|\right\}
$$

$\mathrm{r}_{\mathrm{i}} \quad=$ maksimal kriter referans noktasının i'inci koordinatı;

MOORA tam çarpım tekniğinde ise normalize edilmeden önceki karar matrisinde yer alan $\mathrm{x}_{\mathrm{ij}}$ değerleri ele alınmaktadır. $\mathrm{x}_{\mathrm{ij}}$ değerleri (4) no'lu eşitlikler uygulanarak düzenlenir (Baležentis vd., 2010: 586).

$$
U_{j}=\frac{A_{j}}{B_{j}} \quad A_{j}=\prod_{i=1}^{g} x_{i j} \quad B_{j}=\prod_{i=g+1}^{n} x_{i j}
$$

\section{$\mathrm{U}_{\mathrm{j}}=\mathrm{j}$ 'inci alternatifin genel faydas1}

Her bir alternatif için hedefi maksimum olan kriterlerin değerlerinin çarpımı, hedefi minimum olan değerlerin çarpımına bölündüğünde çıkan sonuçlar sıralanmaktadır. Sonuçta en büyük sonuca sahip olan alternatif, öncelikli olduğuna karar verilen alternatiftir.

Multi-MOORA tekniği sonuçları, oran metodu, referans noktası yaklaşımı ve tam çarpım formunun sonuçlarının birlikte değerlendirilmesiyle ortaya çıkarılmaktadır. Buna göre bu üç metottan en az ikisinin, öncelikli (birinci) olduğunu tespit ettiği alternatif, performans açısından 1. sırada kabul edilmektedir. Aynı sıralama diğer alternatifler için de yapılmaktadır.

Kriterlerin ağırlıklandırılması durumunda oran metodu, referans noktası yaklaşımı ve tam çarpım formuna ilişkin formüller sırasıyla 5-6-7 no'lu eşitliklerde gösterildiği gibi oluşturulmaktadır (Ceballos vd., 2016: 317).

$$
\begin{aligned}
& y_{j}^{*}=\sum_{i=1}^{i=g} x_{i j}^{*} w_{i}-\sum_{i=g+1}^{i=n} x_{i j}^{*} w_{i} \\
& \min _{(j)}\left\{\max _{(i)}\left|r_{i}-x_{i j}^{*} w_{i}\right|\right\} \\
& U_{j}=\frac{A_{j}}{B_{j}} \quad A_{j}=\prod_{i=1}^{g} x_{i j}^{w_{i}} \quad B_{j}=\prod_{i=g+1}^{n} x_{i j}^{w_{i}}
\end{aligned}
$$


$\mathrm{W}_{\mathrm{i}} \quad=\mathrm{i}$ kriterinin ă̆

\subsection{Kapsam ve Veri Seti}

Çalışmada, Borsa İstanbul kapsamında Taş, Toprak (BIST XTAST) endeksinde yer alan çimento firmalarının finansal performansları, 2013-2017 dönemi itibariyle MultiMOORA yöntemi ile incelenecektir. BİST Taş, Toprak Endeksinde yer alan çimento firmaları Tablo 3'te yer almaktadır.

Tablo 3. BİST XTAST Endeksinde Yer Alan Çimento Firmaları

\begin{tabular}{|l|l|}
\hline Kod & Unvan \\
\hline ADANA & Adana Çimento Sanayii T.A.Ş. \\
\hline AFYON & Afyon Çimento Sanayi T.A.Ş. \\
\hline AKCNS & Akçansa Çimento Sanayi ve Ticaret A.Ş. \\
\hline ASLAN & Aslan Çimento A.Ş. \\
\hline BTCIM & Batıçim Batı Anadolu Çimento Sanayii A.Ş. \\
\hline BSOKE & Batısöke Söke Çimento Sanayii T.A.Ş. \\
\hline BOLUC & Bolu Çimento Sanayii A.Ş. \\
\hline BUCIM & Bursa Çimento Fabrikası A.Ş. \\
\hline CMENT & Çimentaş İzmir Çimento Fabrikası T.A.Ş. \\
\hline CIMSA & Çimsa Çimento Sanayi ve Ticaret A.Ş. \\
\hline GOLTS & Göltaş Göller Bölgesi Çimento Sanayi ve Ticaret A.Ş. \\
\hline KONYA & Konya Çimento Sanayii A.Ş. \\
\hline MRDIN & Mardin Çimento Sanayii ve Ticaret A.Ş. \\
\hline NUHCM & Nuh Çimento Sanayi A.Ş. \\
\hline UNYEC & Ünye Çimento Sanayi ve Ticaret A.Ş. \\
\hline
\end{tabular}

Söz konusu firmalara ilişkin mali tablo verilerine, Kamuyu Aydınlatma Platformu (KAP)'ndan ulaşılmıştır. Özkaynaklarında ve dönem kârının (zarar) dağıtımında kontrol gücü olmayan payların yer aldığı mali tablolara sahip firmalar, kapsam dışı tutulmuştur ${ }^{3}$. Buna göre çalışmada finansal performans değerlendirilmesinde ADANA (A1), AFYON (A2), ASLAN (A3), BSÖKE (A4), BOLUC (A5), MRDIN (A6), UNYEC (A7) firmaları ele alınmıştır.

Çalışmada çimento firmalarının finansal performans değerlendirmesinde kriter olarak yedi adet finansal oran ele alınmıştır. Söz konusu finansal oranların belirlenmesinde literatürdeki çalışmalar ve sektör yapısı dikkate alınmıştır. Bu konuda daha sonra yapılacak çalışmalarda farklı likidite, kaldıraç, aktivite ve kârlılık oranları dahil edilerek incelemede farklılaşmaya gidilebilir. Ele alınan söz konusu oranlar Kamuyu Aydınlatma Platformu (KAP)'nda yer alan, ilgili firmalara ait mali tablo verileri esas alınarak hesaplanmıştır. Oranlar ve formülleri Tablo 4'te yer almaktadır.

\footnotetext{
${ }^{3}$ Firmaların bir kısmının finansal tablolarının konsolide, diğerlerinin ise konsolide olmayan tablo olması ve bu doğrultuda seçilen oranların bazı noktalarda göreceli sonuçlar ortaya koyabilecek olması nedeniyle, kontrol gücü olmayan payların bulunduğu konsolide mali tabloya sahip firmalar çalışma kapsamına alınmamıştır.
} 
Tablo 4. Çalışmada Kullanılan Oranlar

\begin{tabular}{|l|l|l|}
\hline Kod & Oranın Adı & Oranın Formülasyonu \\
\hline K1 & Cari Oran & Dönen Varlıklar / Kısa Vadeli Yabancı Kayn. \\
\hline K2 & Maddi Duran Varlıkların Özkaynaklara Oranı & Maddi Duran Varlıklar, net / Özkaynaklar \\
\hline K3 & Finansal Kaldıraç Oranı & Yabancı Kaynaklar / Toplam Aktifler \\
\hline K4 & Alacak Devir Hızı & Hasılat (net satışlar) / Ticari Alacaklar \\
\hline K5 & Aktif Devir Hızı & Hasılat (net satışlar) / Toplam Aktifler \\
\hline K6 & Aktif Kârlılığı & Net Kâr / Toplam Aktifler \\
\hline K7 & Özsermaye Kârlılı̆̆ı & Net Kâr / Özkaynaklar \\
\hline
\end{tabular}

Çimento firmalarının finansal performansının değerlendirilmesinde ele alınan kriterlerden ilki cari orandır. Cari oran bir firmanın dönen varlıkları kısa vadeli borçlarını karşılama gücünü ortaya koymakta olan bir likidite oranıdır. Bir firma için yeterli olup olmaması birtakım etmenlere bağlı olmakla (Akgüç, 2013: 25) birlikte, cari oranın yüksek olması firmanın borç ödeme gücünün yüksekliğini göstermektedir.

Maddi duran varlıkların bilanço değerinden birikmiş amortismanlar indirildikten sonra kalan net değerin özkaynaklara oranı ile hesaplanmakta olan ikinci oran, özsermayenin ne ölçüde maddi duran varlıkların finansmanında kullanıldığını göstermektedir. Sınai firmalarda maddi duran varlıkların tutarının özsermayeden fazla olması, mali açıdan bir güçsüzlük göstergesi olarak yorumlanabilmektedir (Akgüç, 2013: 41)

Varlıkların ne ölçüde yabancı kaynaklarla finanse edildiğini gösteren finansal kaldıraç oranı yükseldikçe, finansal riskin arttığ 1 kabul edilmekte ve oranın sektör ortalamasının üzerinde olmaması önerilmektedir (Okka, 2013: 128).

Alacakların firma tarafindan ne ölçüde etkin yönetildiğini gösteren alacak devir hızının yüksekliği, firmanın etkin tahsilat politikasının mevcudiyetini de gösterebilmektedir (Akgüç, 2013: 45). Bu sayede alacak devir hızı yüksek olan firmaların alacaklara daha az yatırım yaptıkları, maliyetlerinin düştüğü, borç ödeme güçlerinin arttığı, likiditelerinin ve kârlarının yükseldiği söylenebilir (Okka, 2013: 124).

Aktif devir hızı firmanın kârlılı̆̆ı hem de riskliliğini gösteren bir orandır. Bu oran toplam varlıkların içinde duran varlıkların fazla olduğu endüstrilerde daha düşük hesaplanabilmekte (Akgüç, 2013: 58), endüstride aktif devir hızı yüksek olan firmaların, varlıklarını diğer firmalara göre daha verimli kullandıkları ve kapasite kullanım oranlarının daha yüksek olduğu söylenebilir (Okka, 2013: 125).

Aktif kârlılığı, varlıklara yapılan toplam yatırımın ne ölçüde net kâr sağladığını; özkaynak kârlılığı ise ortakları tarafindan sağlanan sermayenin ne ölçüde etkin kullanıldığını ortaya koymaktadır. Söz konusu oranların yüksek olması firmanın yatırım kârlılığının yüksek olduğunu göstermektedir. 
Ele alınan çimento firmalarına ilişkin söz konusu kriterlerin ortalama, medyan, standart sapma, minimum ve maksimum değerlerinin yer aldığı tanımlayıcı istatistikler Tablo 5'te verilmiştir.

Tablo 5. Tanımlayıcı İstatistiksel

\begin{tabular}{lccccccc} 
& K1 & K2 & K3 & K4 & K5 & K6 & K7 \\
\hline Ortalama & 2,79 & 0,79 & 0,30 & 3,38 & 0,56 & 0,12 & 0,16 \\
\hline Medyan & 2,31 & 0,78 & 0,33 & 3,09 & 0,58 & 0,13 & 0,17 \\
\hline Standart Sapma & 1,33 & 0,42 & 0,14 & 0,98 & 0,15 & 0,06 & 0,07 \\
\hline Minimum & 1,37 & 0,38 & 0,15 & 2,27 & 0,29 & 0,02 & 0,02 \\
\hline Maksimum & 5,42 & 1,49 & 0,49 & 5,10 & 0,72 & 0,18 & 0,25 \\
\hline
\end{tabular}

Ortalama değerine göre sektörün ilgili kriterler bazında durumu ele alınabilir. Cari oran (K1) değeri 2,79 olarak hesaplanmıştır. Buna göre sektörde dönen varlıkların kısa vadeli borçları karşılama gücünün bulunduğu belirtilebilir. Maddi duran varlıkların özkaynaklara oranı (K2) 0,79'dur. $\mathrm{Bu}$ doğrultuda sektörde maddi duran varlıkların finansmanında özsermayenin yeterli olduğu söylenebilir. Finansal kaldıraç oranı (K3) ele alındığında sektörde, varlıkların finansmanında \%30 oranında yabancı kaynak kullanıldığı görülmektedir. 3,38 olarak hesaplanan alacak devir hızı (K4) değerine göre sektördeki firmaların ticari alacaklarının 3,38 katı kadar net satış gerçekleştirdiği görülmektedir. Aktif devir hızı (K5) değeri 0,56 hesaplanmıştır. Buna göre sektörde varlıkların yaklaşık yarısı kadar satış yapılmaktadır. Sektörde aktif kârlılığ 1 (K6) 0,12 iken özsermaye kârlılı̆g 1 (K7) 0,16'dır. Sektörde yapılan toplam yatırımın \% 12'si, sermayenin ise \%16'si kadar kâr elde edilmektedir.

Medyan değerlerinin ortalama değerlerine yakınlığı sektördeki firmaların birbirinden çok farklı olmayan ve ortalamaya yakın oran sonuçlarına sahip olduğunu göstermektedir. Standart sapma değerlerine göre de firmaların kriterlerinin ortalamaya yakın olduğu, geniş dağılım göstermediği söylenebilir. Her bir kritere ilişkin, firmaların sahip olduğu en düşük ve en yüksek değerler de Tablo 5 'te görülmektedir.

\section{BULGULAR}

Borsa İstanbul Taş- Toprak endeksinde yer alan çimento firmalarının 2013-2017 dönemi ele alınarak, finansal performans analizi için çok kriterli karar verme tekniklerinden MOORA'nın oran metodu, referans noktası yaklaşımı ve tam çarpım formundan yararlanılacak ve bu yaklaşımlar sonucu Multi-MOORA ile değerlendirme yapılmıştır. Bu çalışmada yapılan değerlendirme, inceleme dönemine ilişkin verilerin ortalaması alınarak yapılmıştır.

Oran metoduna göre, her kriter (oran) için, çimento firmalarının her birinin finansal oranlarının kareleri toplamının karekökü alınmış ve her firmanın ilgili finansal oranı, bulunan bu sonuca bölünerek normalize edilmiştir ${ }^{4}$. Bulunan sonuçlar, her firmanın ilgili oran için normalize edilmiş değerini vermektedir. Her bir firma için; maksimum olması beklenen finansal oranların toplamından, minimum olması beklenen finansal oranların toplamı

\footnotetext{
${ }^{4}$ Normalize edilmeden önceki finansal oranlar Tablo 8'deki tam çarpım formu matrisinde görülmektedir.
} 
çıkarılmıştır ${ }^{5}$. Elde edilen sonuçlar her bir çimento firmasının, performans kriterini oran metoduna göre vermektedir. Elde edilen değerlere büyüklük sıralaması yapıldığında, değerler arasında en büyük olan, finansal performansı en yüksek firmayı; en küçük olan ise ilgili kriterlere göre performansı en düşük firmayı göstermektedir. Oran metoduna göre analiz sonuçları Tablo 6'da gösterilmektedir.

Tablo 6. Oran Metodu Normalize Edilmiş Karar Matrisi

\begin{tabular}{rrrrrrrrr|r} 
& $\mathrm{K} 1$ & $\mathrm{~K} 2$ & $\mathrm{~K} 3$ & $\mathrm{~K} 4$ & $\mathrm{~K} 5$ & $\mathrm{~K} 6$ & $\mathrm{~K} 7$ & $y_{j}^{*}$ & $\mathrm{~S}$ \\
\hline A1 & 0,426 & 0,163 & 0,191 & 0,333 & 0,310 & 0,382 & 0,342 & 1,439 & 3 \\
\hline A2 & 0,273 & 0,640 & 0,557 & 0,467 & 0,350 & 0,198 & 0,285 & 0,376 & 6 \\
\hline A3 & 0,170 & 0,336 & 0,414 & 0,245 & 0,384 & 0,317 & 0,368 & 0,733 & 5 \\
\hline A4 & 0,286 & 0,509 & 0,524 & 0,550 & 0,193 & 0,069 & 0,048 & 0,113 & 7 \\
\hline A5 & 0,241 & 0,350 & 0,373 & 0,315 & 0,476 & 0,485 & 0,539 & 1,333 & 4 \\
\hline A6 & 0,354 & 0,188 & 0,203 & 0,338 & 0,382 & 0,463 & 0,419 & 1,565 & 2 \\
\hline A7 & 0,671 & 0,185 & 0,166 & 0,308 & 0,473 & 0,510 & 0,445 & 2,056 & 1 \\
\hline
\end{tabular}

\section{A: İncelenen firmalar \\ K: Kriterler $y_{j}^{*}$ : Değerlendirme S: Siralama}

İlgili finansal oranlara göre yapılan sıralamanın yer aldığı Tablo 6'daki oran metodu sonuçlarına göre, Ünye Çimento (A7) en yüksek finansal performans değerine sahiptir. Batısöke Söke Çimento (A4) ise performans sıralamasında oran metoduna göre son sırada yer almaktadır. Ünye Çimento'dan sonra, finansal performans bakımından Mardin Çimento (A6) yer almaktadır.

Diğer bir yaklaşım olan referans noktası yaklaşımına göre, maksimum olması beklenen her bir kriter için en büyük değer, minimum olması beklenen K2 ve K3 kriterleri için ise en küçük değer ilgili kriterin referansı $\left(\mathrm{r}_{\mathrm{i}}\right.$ olarak belirlenmektedir. $\mathrm{Bu}$ işlemden sonra Tablo 6'daki normalize edilmiş matriste yer alan her bir kriter $(\mathrm{K} 1, \ldots, \mathrm{K} 7)$ ile ilgili kriterin referansı $\left(\mathrm{r}_{\mathrm{i}}\right)$ arasındaki farkın mutlak değer alınarak yeni bir matris hazırlanmıştır. Bu matris Tablo 7'de yer almaktadır. Söz konusu matrise göre her çimento firmasının maksimum kriteri $\left(\max _{(i)}\left|r_{i}-x_{i j}^{*}\right|\right)$ belirlenmiştir. Belirlenen bu değerler ele alındığında, en küçük değer, finansal performansı en yüksek olan firmayı göstermektedir.

\footnotetext{
${ }^{5}$ Maddi Duran Varlıkların Özkaynaklara Oranı ve Finansal Kaldıraç Oranı minimum; diğer oranlar ise maksimum olması beklenen oranlardır.
} 
Tablo 7. Referans Noktası Yaklaşımı Matrisi

\begin{tabular}{|c|c|c|c|c|c|c|c|c|c|}
\hline & K1 & K2 & K3 & K4 & K5 & K6 & K7 & $\max _{(i)}\left|r_{i}-x_{i j}^{*}\right|$ & $\mathrm{S}$ \\
\hline & mak & $\min$ & $\min$ & mak & mak & mak & mak & & \\
\hline $\mathrm{r}_{\mathrm{i}}$ & 0,671 & 0,163 & 0,166 & 0,550 & 0,476 & 0,510 & 0,539 & & \\
\hline $\mathrm{A} 1$ & 0,245 & 0,000 & 0,024 & 0,217 & 0,167 & 0,128 & 0,197 & 0,2452 & 2 \\
\hline $\mathrm{A} 2$ & 0,398 & 0,476 & 0,391 & 0,084 & 0,126 & 0,312 & 0,253 & 0,4764 & 5 \\
\hline $\mathrm{A} 3$ & 0,502 & 0,173 & 0,247 & 0,306 & 0,093 & 0,193 & 0,171 & 0,5016 & 7 \\
\hline $\mathrm{A} 4$ & 0,385 & 0,346 & 0,358 & 0,000 & 0,283 & 0,441 & 0,491 & 0,4910 & 6 \\
\hline A5 & 0,430 & 0,187 & 0,206 & 0,236 & 0,000 & 0,025 & 0,000 & 0,4302 & 4 \\
\hline A6 & 0,318 & 0,025 & 0,037 & 0,212 & 0,094 & 0,047 & 0,120 & 0,3175 & 3 \\
\hline A7 & 0,000 & 0,021 & 0,000 & 0,243 & 0,003 & 0,000 & 0,094 & 0,2426 & 1 \\
\hline
\end{tabular}

$\mathrm{r}_{\mathrm{i}}$ : referans noktas 1

S: Siralama

Tablo 7'ye göre finansal performans bakımından Ünye Çimento (A7) ilk sırada, Aslan Çimento (A3) son sırada yer almaktadır. Bu yaklaşımına göre finansal performans bakımından ikinci sırada Adana Çimento (A1) yer almaktadır.

Tam çarpım formunda, normalize edilmemiş oranlar kullanılmaktadır. Her firma (alternatif) için, maksimum olması beklenen kriterlerin çarpımı, minimum olması beklenen kriterlerin çarpımına bölünerek bir değer hesaplanmış ve sonuçlar Tablo 8'de gösterilmiştir. Hesaplama sonucunda ortaya çıkan en büyük değer, finansal performansı yüksek olan firmayı göstermektedir.

Tablo 8'de verilen değerlere göre finansal performans bakımından ilk sırada Ünye Çimento (A7), ikinci sırada Mardin Çimento (A6), son sırada ise Batısöke Söke Çimento (A4) yer almaktadir.

Tablo 8. Tam Çarpım Formu Matrisi

\begin{tabular}{ccccccccc|c} 
& $\mathrm{K} 1$ & $\mathrm{~K} 2$ & $\mathrm{~K} 3$ & $\mathrm{~K} 4$ & $\mathrm{~K} 5$ & $\mathrm{~K} 6$ & $\mathrm{~K} 7$ & $\mathrm{U}_{\mathrm{j}}=\mathrm{A}_{\mathrm{j}} / \mathrm{B}_{\mathrm{j}}$ & $\mathrm{S}$ \\
\hline A1 & 3,438 & 0,380 & 0,167 & 3,085 & 0,469 & 0,133 & 0,161 & 1,6823 & 3 \\
\hline A2 & 2,204 & 1,491 & 0,487 & 4,321 & 0,531 & 0,069 & 0,134 & 0,0643 & 6 \\
\hline A3 & 1,368 & 0,784 & 0,361 & 2,267 & 0,581 & 0,111 & 0,173 & 0,1217 & 5 \\
\hline A4 & 2,307 & 1,186 & 0,458 & 5,097 & 0,292 & 0,024 & 0,022 & 0,0034 & 7 \\
\hline A5 & 1,944 & 0,816 & 0,326 & 2,916 & 0,721 & 0,169 & 0,253 & 0,6588 & 4 \\
\hline A6 & 2,854 & 0,438 & 0,177 & 3,132 & 0,579 & 0,161 & 0,197 & 2,1164 & 2 \\
\hline A7 & 5,417 & 0,430 & 0,145 & 2,850 & 0,716 & 0,178 & 0,209 & 6,5800 & 1 \\
\hline
\end{tabular}

$\mathrm{Uj}=\mathrm{j}$ 'inci alternatifin genel faydası S: Siralama

Oran metodu, referans noktası yaklaşımı ve tam çarpım formu birbirinden farklı sonuçlar verebilmektedir. Multi-MOORA tekniğinde, bu üç metodun sonuçları bir arada 
değerlendirilmekte ve en az ikisinde ortak çıkan sonuç, finansal performans sonucunu göstermektedir. Bu doğrultuda yapılan değerlendirme Tablo 9'da görülmektedir.

Tablo 9. Multi-MOORA Performans Sıralama Sonuçları

\begin{tabular}{|lcccc|}
\hline & Oran & Referans noktası & Tam çarpım & Multi-Moora \\
\hline A1 & 3 & 2 & 3 & 3 \\
\hline A2 & 6 & 5 & 6 & 6 \\
\hline A3 & 5 & 7 & 5 & 5 \\
\hline A4 & 7 & 6 & 7 & 7 \\
\hline A5 & 4 & 4 & 4 & 4 \\
\hline A6 & 2 & 3 & 2 & 2 \\
\hline A7 & 1 & 1 & 1 & 1 \\
\hline
\end{tabular}

\begin{tabular}{|ll|}
\hline \multicolumn{2}{|c|}{ Siralama } \\
\hline UNYEC & 1 \\
\hline MRDIN & 2 \\
\hline ADANA & 3 \\
\hline BOLUC & 4 \\
\hline ASLAN & 5 \\
\hline AFYON & 6 \\
\hline BSOKE & 7 \\
\hline
\end{tabular}

Tablo 9'da görüldüğü üzere finansal performans açısından üç yöntemde ilk sırada Ünye Çimento yer almaktadır. Buna göre BİST Taş, Toprak Endeksinde 2013-2017 döneminde yer alan firmalardan ele alınanlardan Ünye Çimento, seçilen kriterlere göre değerlendirme yapıldığında, finansal performans açısından ilk sırada yer almaktadır.

Finansal performans açısından üç yöntemde ikinci sırada çoğunlukla (oran metodu ve tam çarpım formunda) Mardin Çimento yer almaktadır. Diğer firmalara ilişkin değerlendirme Tablo 9'da görüldügü gibi, benzer şekilde yapılabilir.

\section{SONUÇ}

İşletmelere ilişskin faaliyet planlamaları ve performans değerlendirmesi hususunda alternatifler üzerinde karar verilmesine ilişkin çalışmalarda, çok kriterli karar verme yöntemleri, analiz yöntemi olarak tercih edilmektedir. Çok kriterli karar verme teknikleri arasında yer alan bütün yöntemler kıyaslandığında, MOORA tekniğinin güvenilirliğinin iyi olması başta olmak üzere, tercih edilme avantajlarının bulunmakta olduğu belirtilmektedir. $\mathrm{Bu}$ çalışmada Multi-MOORA tekniği ile 2013-2017 döneminde Borsa İstanbul Taş, Toprak Endeksinde yer alan çimento firmalarının finansal performansları incelenmiştir.

MOORA tekniğinin, oran metodu, referans noktası yaklaşımı ve tam çarpım formu olarak sıralanan metotları farklı sonuçlar ortaya koyabilmektedir. Bu nedenle her üç tekniğin sonuçlarının bir arada değerlendirilerek baskınlık karşılaştırmasının yapılması ve karar verilecek alternatif için en az iki tekniğin aynı sonucu belirtmesi esasına dayanan MultiMOORA yaklaşımından istifade edilmektedir.

Çimento firmalarının finansal performansı, çalışmaya dahil edilen finansal oranlar temelinde Multi-MOORA tekniğine göre değerlendirilmiştir. Metotların tamamında ve bu doğrultuda Multi-MOORA değerlendirmesine göre, en iyi finansal performansa sahip olan çimento firmasının Ünye Çimento olduğu görülmüştür.

Ünye Çimentonun cari oran, aktif devir hızı ve kârlılık gibi maksimum olması beklenen kriterler bakımından en yüksek değere sahip olması, finansal kaldıraç gibi minimum olması beklenen kriterler bakımından ise en düşük değer sahip olması, yüksek finansal performans göstermesinde etkilidir. 
Finansal performans bakımından ilk 3 sırada yer alan Ünye Çimento, Mardin Çimento ve Adana Çimento firmaları ele alındığında çimento sektöründe finansal performansı etkileyen ağırlıklı kriterlerin cari oran, finansal kaldıraç, aktif devir hızı, aktif ve özsermaye kârlılığ1 olduğu gözlemlenmektedir. Bu doğrultuda alanda bundan sonra yapılacak çalışmalarda ele alınan kriterlerin ağırlıklandırılmasını sayısal bir şekilde ortaya koyan AHP gibi modellerin de çalışmaya dahil edilmesi uygun olabilir.

Literatürde yer alan, farklı analiz yöntemine sahip çalışma sonuçları dikkate alındığında, bu çalışmada nispi olarak yüksek performansa sahip bulunan Ünye, Mardin, Adana Çimento firmalarının, ilgili çalışmaların bir kısmında yüksek performansa sahip olduğu gözlenmektedir.

$\mathrm{Bu}$ çalışmada yapılan değerlendirme, inceleme dönemine ilişkin verilerin ortalaması alınarak yapılmıştır. Her bir yıla ilişkin ayrı birer performans değerlendirmesi yapıldığında farklı sonuçların ortaya çıkabileceği düşünülebilir. Diğer bir ifade ile analizler sonucunda dönemsel olarak performansı yüksek veya düşük olan firmalar yıl bazında ve ayrıca gelecek dönemlerde, farklı performansa sahip olabilirler. $\mathrm{Bu}$ doğrultuda yapılacak analizlerde bu durum ele alınabilir.

Öte yandan firmaların performanslarına ilişkin yapılan incelemelerde, ele alınan finansal oranların değişmesi farklı sonuçlar ortaya çıkarabilmektedir. Bu da araştırmacılar için değişik bir bakış açısı yaratmaktadır. Bu noktadan yola çıkarak daha sonra yapılacak çalışmalarda dönem ve kriter değişikliğine gidilerek veya analiz tekniğinde yapılacak bir değişiklikle, ele alınan firmalara ilişkin performans değerlendirmesine ilişkin farklı bulgulara ulaşılabilir.

\section{KAYNAKLAR}

Akgüç, Öztin (2013), Finansal Yönetim, 9. Baskı, Avcı1 Basım Yayın, İstanbul.

Baležentis, Alvyda- Baležentis, Tomas- Valkauskas, Romualdas (2010), "Evaluating Situation of Lithuania in the European Union: Structural Indicators and MULTIMOORA Method", Technological and Economic Development of Economy, 16 (4), pp.578-602.

Brauers, Willem Karel M.- Zavadskas, Edmundas Kazimieras (2006), "The MOORA Method and Its Application to Privatization in a Transition Economy", Control and Cybernetics. Informatica", 35 (2), pp.445-469.

Brauers, Willem Karel M.- Zavadskas, Edmundas Kazimieras (2012), "Robustness of MULTIMOORA: A Method for Multi-Objective Optimization”, Informatica, 23 (1), pp.1-25.

Ceballos, Blanca- Lamata, María Teresa- Pelta, David A. (2016), “A Comparative Analysis of Multi-Criteria Decision-Making Methods”, Prog Artif Intell, 5, pp.315-322. 
Cenger, Hatice (2011), "İMKB'de İşlem Gören Çimento Şirketlerinin Performanslarının Ölçülmesinde Veri Zarflama Analizi Yaklaşımı”, Atatürk Üniversitesi İktisadi ve İdari Bilimler Dergisi, 25(3-4), ss.31-44.

Ceyhan, İsmail Fatih- Demirci, Ferhat (2017), "MULTIMOORA Yöntemiyle Finansal Performans Ölçümü: Leasing Şirketlerinde Bir Uygulama”, Batın Üniversitesi İİBF Dergisi, 8 (15), ss.277-296.

Dumanoğlu, Sezayi (2010), “IMMKB’de İşlem Gören Çimento Şirketlerinin Mali Performanslarının TOPSİS Yöntemi ile Değerlendirilmesi”, Marmara Üniversitesi İIBF Dergisi, 29 (2), ss.323-339.

Ege, İlhan- Yaman, Serdar (2017), “TOPSİS ve MOORA Yöntemleri ile Ölçülen Finansal Performansın Pay Getirilerine Etkisi: BİST Çimento-Beton İşletmeleri Üzerine Bir Uygulama", AL-FARABI 1st International Congress on Social Sciences, May 11-14 2017, s.494.

Ertuğrul, İrfan- Karakaşoğlu, Nilsen (2009), "Performance Evaluation of Turkish Cement Firms With Fuzzy Analytic Hierarchy Process and TOPSIS Methods", Expert Systems with Applications, 36, pp.702-715.

Karsak, E. Ertuğrul- İşcan, Firuzan (2000), “Çimento Sektöründe Göreli Faaliyet Performanslarının Ağırlık Kısıtlamaları ve Çapraz Etkinlik Kullanılarak Veri Zarflama Analizi ile Değerlendirilmesi”, Endüstri Mühendisliği Dergisi, 11 (3), ss.2-10.

Metin, Sevda- Yaman, Serdar- Korkmaz, Turhan (2017), "Finansal Performansin TOPSIS ve MOORA Yöntemleri İle Belirlenmesi: BİST Enerji Firmaları Üzerine Karşılaştırmalı Bir Uygulama", Kahramanmaraş Sütçü İmam Üniversitesi Sosyal Bilimler Dergisi, 14 (2), ss.371-394.

Okka, Osman (2013), Finansal Yönetim Teori ve Çözümlü Problemler, 5. Basım, Nobel Akademik Yayıncılık, Ankara.

Ömürbek, Nuri- Aksoy, Esra (2017), “Ulusal Verimlilik İstatistiklerine Göre İmalat Sektörlerinin Performansının Değerlendirmesinde MULTİ-MOORA Yönteminin Uygulanması", Süleyman Demirel Üniversitesi İktisadi ve İdari Bilimler Fakültesi Dergisi, 22 (1), ss.1-19.

Ömürbek, Nuri- Özcan, Aslı (2016), “BIST’de İşlem Gören Sigorta Şirketlerinin MULTIMOORA Yöntemiyle Performans Ölçümü”, Uluslararası İşletme, Ekonomi ve Yönetim Perspektifleri Dergisi, 1 (2), ss.64-75.

Özden, Ünal H.- Deniz Başar, Özlem- Bağdatlı Kalkan, Seda (2012), “İMKB'de İşlem Gören Çimento Sektöründeki Şirketlerin Finansal Performanslarının VİKOR Yöntemi ile Suralanması", İstanbul Üniversitesi İktisat Fakültesi Ekonometri ve İstatistik Dergisi, 17, ss.23-44.

Raikar, Avinash V. (2018), “An Analytical Study of the Cement Sector and Selected Cement Companies in India by using Multi Criteria Decision Making (MCDM) Technique of 
Analytic Hierarchy Process (AHP) and VIKOR", International Journal of Research in Management, Economics and Commerce, 8 (5), pp.1-11.

Rekabet Kurumu (2016), "Çimento Sektör Araştırması (Haziran 2016)" http://www.rekabet.gov.tr/Dosya/sektor-raporlari/12-cimento-sektor-raporu-pdf (10.04.2018)

Rezaie, Kamran- Ramiyani Sara Saeidi- Nazari-Shirkouhi, Salman- Badizadeh, Ali (2014), "Evaluating Performance of Iranian Cement Firms Using An İntegrated Fuzzy AHPVIKOR Method", Applied Mathematical Modelling, 38, pp.5033-5046.

Sakarya, Şakir ve Akkuş, Hilmi Tunahan (2015), "Finansal Performansın Ölçülmesinde Geleneksel Oranlar ile Nakit Akım Oranlarının Karşılaştırmalı Analizi: BİST Çimento Şirketleri Üzerine TOPSİS Yöntemi ile Bir Uygulama”, Afyon Kocatepe Üniversitesi İ̈BF Dergisi, 17 (1), ss.109-123.

Türkiye İş Bankası (2016), “Çimento Sektörü (Mayıs 2016)” https://ekonomi.isbank.com.tr/ UserFiles/pdf/sr201604_CimentoSektoru.pdf (20.06.2018)

Türkiye Sınai ve Kalkınma Bankası A.Ş.-TSKB- (2018), "Sektörel Görünüm: İnşaat, Çimento Seramik (Mayis 2018)", http://www.tskb.com.tr/i/content/3540_1_Sekt\%C3\%B6rel\% 20G\%C3\%B6r\%C3\%BCn\%C3\%BCm_\%C4\%B0n\%C5\%9Faat\%20\%C3\%87imento \%20ve\%20Seramik\%20(May\%C4\%B1s).pdf (20.06.2018)

http://www.tcma.org.tr/index.php?page=icerikgoster\&menuID=28(20.06.2018)

http://www.tcma.org.tr/index.php?page=icerikgoster\&menuID=38(20.06.2018)

http://www.tcma.org.tr/index.php?page=icerikgoster\&menuID=43(20.06.2018) 